\title{
Noise Induced Hearing Loss in Glass Factory Workers in Delta State Nigeria: An 8 year follow up.
}

\section{Original Article}

\author{
Okolugbo Nekwu Emmanuel
}

Department of Surgery, Delta State University, Abraka.

\begin{abstract}
Background: Noise induced hearing loss is a well known recognized hazard in factory workers. This is due to the fact that the level of noise in most factories exceed the WHO acceptable limits. This was an 8 year follow up study on glass factory workers to determine the effect of noise on their hearing status over that period.

Materials and Methods: Audiometry was carried out on the factory workers using a diagnostic audiometer. This was repeated after 8 years. All the workers had their ears examined prior to Audiometry which was done in a quiet area in the factory clinic. Thereafter data was collected and analysed.

Results: The subsequent screening showed that all the workers had increased threshold of hearing and the Prevalence rate of hearing impairment had increased from $9.1 \%$ to $40.8 \%$. All workers admitted to intermittent use of personal protective devices (ear muffs/ear plugs) despite being counselled on their use 8 years earlier.

Conclusion: Hearing Conservation measures should be instituted in factories. Pre-employment screening should be mandatory as well as annual audiological screening and the labour laws should be strengthened to ensure adequate compliance by industries.
\end{abstract}

Key Words: Audiometry, Factory Workers, Hearing Impairment, Noise, Screening.

Received: 22 February 2020, Accepted: 4 March 2020

Corresponding Author: Okolugbo Nekwu Emmanuel, Department of Surgery, Delta State University, Abraka., Tel.: 2348038011767, E-mail: nekouokolugbo@yahoo.com

ISSN: 2090-0740, July 2020 Vol.21, No.2

\section{INTRODUCTION}

Auditory Noise induced hearing loss is a well known recognized hazard in factory workers. This is due to the fact that threshold levels of noise in most production factories exceed the WHO acceptable level of noise. Also due to poor resources in developing countries we find workers put in longer hours than the recommended maximum hours of 8 hours to make up for the shortfall in the number of staff.

It is also required of factory workers to do an annual audiological screening of their $\operatorname{staff}^{[1,2]}$ as this will be helpful in monitoring any changes in their hearing, however as found in this study, this was not done and thus early changes were not noticed.

\section{METHODOLOGY:}

This was a follow up study carried out on 22 factory workers in Delta State, Nigeria. Noise levels in the factory raged from $85 \mathrm{dBA}$ to $116 \mathrm{dBA}$ at the location with the highest noise level, taken with the SPL meter (radio shack).

Exclusion criteria included anyone not present in the initial study done in 2011, ear diseases like chronic suppurative otitis media. Those with wax in the ears had the ears syringed and the test was repeated.

All workers admitted to irregular use of plugs/ear muffs. Audiometry was carried out using a clinical interacoustic audiometer. Thereafter data was analysed.

The pure tone average was calculated by adding the thresholds obtained at 500, 1000 and $2000 \mathrm{~Hz}$ and dividing the result by 3 .

\section{RESULTS}

Total number of workers recruited into the study were 22. All were Male within the $3^{\text {rd }}$ and $5^{\text {th }}$ decades of life. This gave a total number of 44 ears. Results obtained in 2011 showed that 20 workers had bilateral normal hearing and showed that 2 workers with a prevalence rate of $9.1 \%$ had bilateral hearing impairment.

In the follow up study done in 2019. 3 workers (13.6\%) had bilateral hearing impairment whilst 3 (13.9\%) had left hearing impairment, and another 3 worker had right hearing impairment. Thus the prevalence rate of those with hearing impairment had risen from $9.1 \%$ to $40.8 \%$ in 8 years.

The degree of hearing impairment all fell within the range of mild hearing impairment apart from one worker who had progressed from having bilateral mild hearing loss in 2011 to now having moderate hearing loss on the left and mild hearing loss on the right. It is important to note that all the factory workers including those that had normal hearing all had increased thresholds of hearing when compared with the results obtained 8 years earlier. 
Emmanuel

REPORT OF AUDIOMETRIC SCREENING FOR EMPLOYEES OF GLASS PLANT IN DELTA STATE

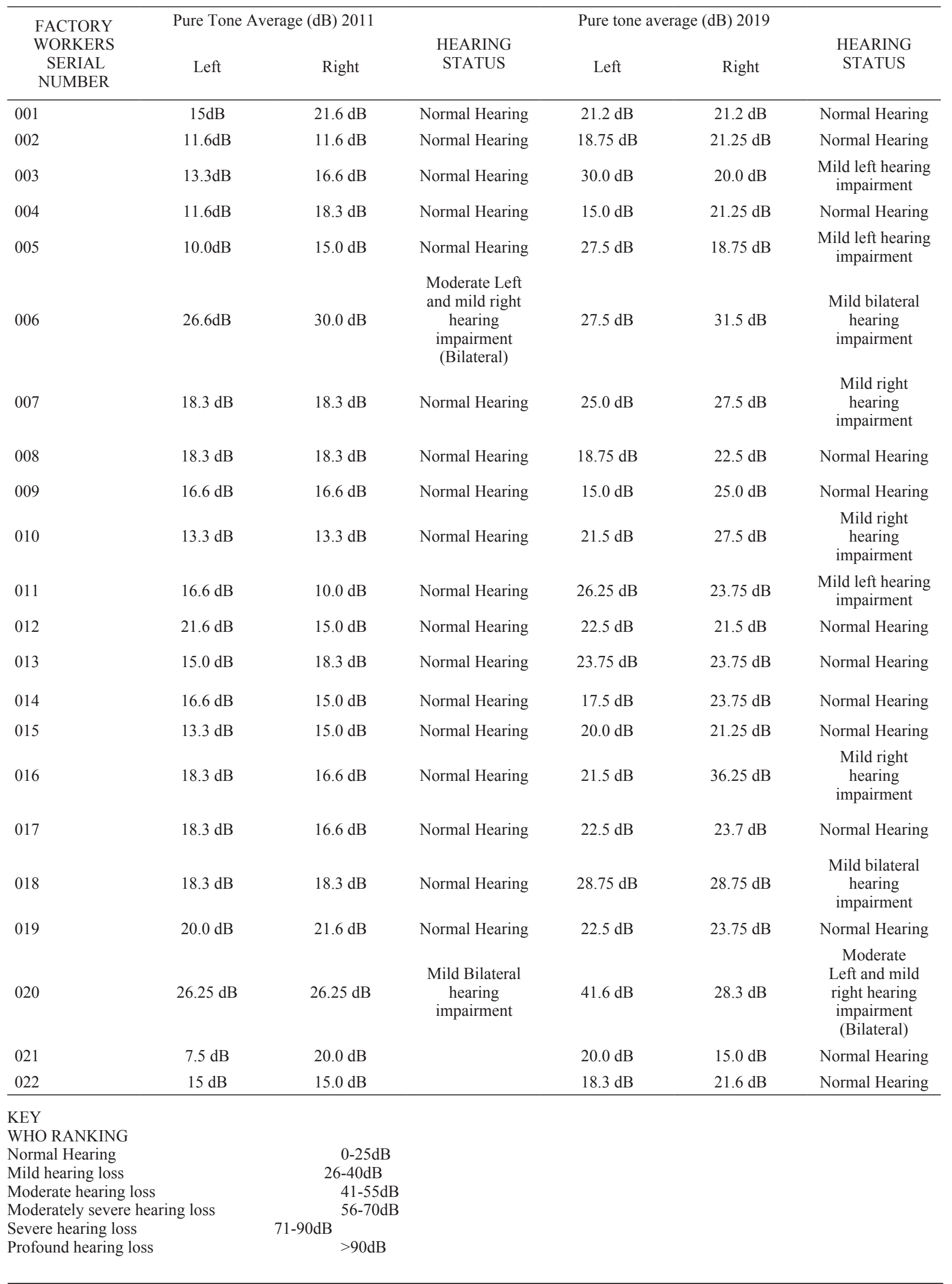


STATUS REPORT FOR THE SCREENED EMPLOYEES OF GLASS PLANT IN DELTA STATE

\begin{tabular}{|c|c|c|c|c|}
\hline \multirow[b]{2}{*}{ HEARING STATUS } & \multicolumn{4}{|c|}{ NUMBER OF EMPLOYEES } \\
\hline & 2011 & $\begin{array}{l}\text { PREVALENCE } \\
\text { RATE }(\%)\end{array}$ & 2019 & $\begin{array}{l}\text { PREVALENCE } \\
\text { RATE }(\%)\end{array}$ \\
\hline NORMAL HEARING & 20 & 90.9 & 13 & 59.1 \\
\hline $\begin{array}{l}\text { LEFT HEARING } \\
\text { IMPAIRMENT }\end{array}$ & 0 & 0 & 3 & 13.6 \\
\hline $\begin{array}{l}\text { RIGHT HEARING } \\
\text { IMPAIRMENT }\end{array}$ & 0 & 0 & 3 & 13.6 \\
\hline $\begin{array}{l}\text { BILATERAL HEARING } \\
\text { IMPAIRMENT }\end{array}$ & 2 & 9.1 & 3 & 13.6 \\
\hline
\end{tabular}

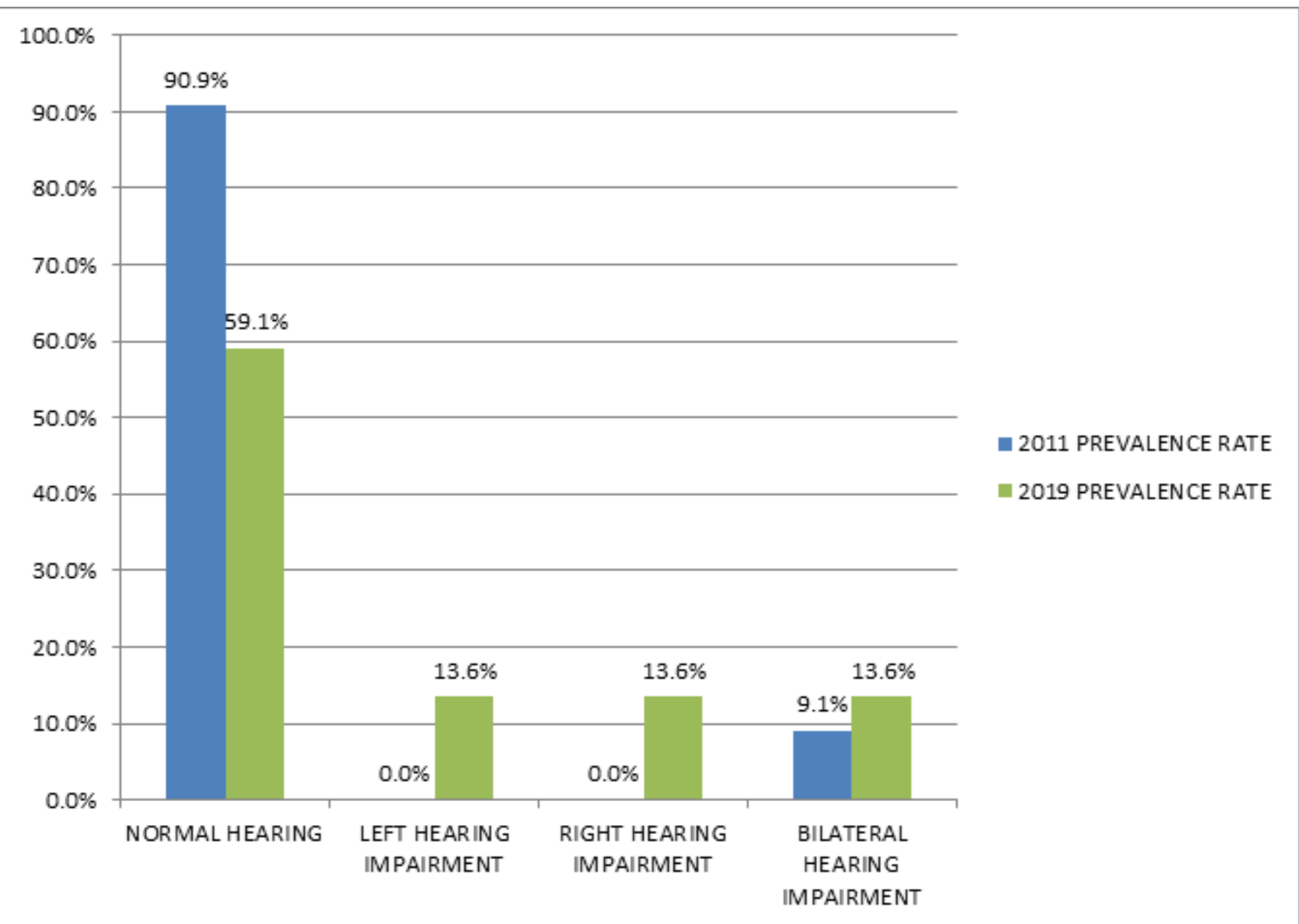

Fig 1: a chart showing the prevalence rate of hearing loss amongst employees of Glass plant in Delta State in the year 2011 and 2019.

SUMMARY

Total : 44 ears

Ears with hearing impairment

Bilateral Hearing Loss

Left SNHL

Right SNHL

13 employees have bilateral normal hearing in the year 2019 as against 20 employees in year 2011
12 ears in 2019 as against 2 ears in 2011

3 workers (6 ears)$$
3 \text { ears }
$$

\section{DISCUSSION}

The Noise induced hearing loss is the most common health problem arising from exposure to excessive noise $^{[1,2]}$. This is quite a preventable disorder ${ }^{[3,4]}$. Thus in low resource economies where the cost of hearing aids are not within reach of most of the persons there, it is imperative that hearing conservation programs are put in place especially in factories where the workers are exposed to usually noises outside the WHO acceptable range. It is estimated that 10 million workers suffer from NIHL in USA ${ }^{[5]}$. 
Emmanuel

Occupational safety and health administration laws sets the limits of permissible exposure limit (PEL) workers at 90dBA. For all workers for an 8 hours period and also requires that all workers exposed to noise levels more than $85 \mathrm{~dB}$ be screened annually 2 . This will help detect increases in threshold of hearing annually and interventions could be made before irreversible damage is done ${ }^{[6]}$.

However as in the case of the case this factory there was an 8year gap in the screening of its staff which is highly unacceptable, it is important to note that noise induced hearing loss is poorly studied in Africa and Nigeria $^{[7,8]}$.

The prevalence of hearing loss amongst the 22 staff recruited into the follow-up study after 8 years was found to be $40.9 \%$ which was quite high compared to $9.1 \%$ 8years earlier. All workers who had been given hearing conservation lectures by the researcher 8 years prior to the follow up study admitted to inconsistent use of personal protective devices (ear muffs/ear plugs) which would have assisted in preventing noise induced hearing loss.

In the follow up study, there was no predeliction to any ear. There was a prevalence rate of $13.6 \%$ of hearing loss for the right ear and $13.6 \%$ of hearing loss for the left ear.

Also very significantly all the workers had increased threshold rates noted across all the frequency ranges. This implies that a follow up study in a few years will likely get a much higher prevalence rate of hearing impairment and also an increase in its severity. Most workers with mild hearing loss are not aware of this ${ }^{[9,10]}$ This is most commonly detected by audiometric screening and thus should be imperative in factory workers. All the workers in this study with hearing impairment were noted to be in the range of mild hearing loss except one of the workers who had indeed progressed from mild hearing loss eight years earlier to moderate hearing loss.

It is also quite important to note that none of these workers had pre-employment screening before they joined the company which would have helped in hearing a baseline for their hearing threshold/status noted.

\section{CONCLUSION}

Hearing conservation programs should be instituted as a matter of urgency in our factories so that workers are diligent in the use of their personal protective devices, also annual audiometric screening should be mandatory as well as pre-employment screening. This will help in detecting early stages of noise induced hearing loss and would make room for better management.

\section{CONFLICT OF INTEREST}

There are no conflicts of interest.

\section{REFERENCES}

1. World Health Organisation. Prevention of noise induced hearing loss Report of a WHO - PDH informal Consultation Geneva 28 - 30 October 1997. No 3 in the series. Strategies for prevention for deafness and hearing impairment 1997, WHO PDH 98.5

2. Occupational Safety and Health Administration: Noise exposure computation. Regulation (Standards 29 CFR) Occupational Safety and Health Standards: Occupational Health and Environment Control (G); 1996 (61 FR 9227): 1910.95

3. Dunn DE, Robinowitz PM Noise in textbook of Clinical Occupational and environmental Medicine. L. Rosenstock Ed. Pp 426 - 430, Elsevier Saunders, Philadelphia Pa. USA. 2nd Edition 2005.

4. Mehrdad M, Seyyed JM, Amir HM, BAhaloo M, Mollasadeghi A, Darari MH Effect of workplace Noise on Hearing ability in Tile and Ceramic industry workers in Iran: A 2 year follow up study. The scientific world journal 2013 AD 923731

5. US Department of Labour, Occupational Safety and Health administration (USDOL OSHA), Noise and Hearing Conservation 2002

6. Rosle G. Progression of hearing loss caused by occupational noise. Scandinavian Audiology 23; $13-371994$.

7. Ologe FE, Akande TM, Olajide TG. Noise exposure, awareness, attitudes and use of hearing protection in a steel rolling mill in Nigeria. Occupational Medicine 2005, 55: $487-489$.

8. Akande TM, Ologe FE. Noise induced hearing loss in the middle belt of Nigeria. Postgraduate Doctor Africa 2003, 25; 4: $81-82$.

9. Hong O. Hearing loss among operating Engineers in American Construction industry. International Archives of Occupational and Environmental Health 2005, 78; 7: $565-574$.

10. Thonson J, Robinson ST. Occupational hearing loss, Current Occupational and environmental medicine. J Ladou Ed 104 - 110. Mc Graw Hill 3rd edition 2007. 